\title{
Melt pond fraction and spectral sea ice albedo retrieval from MERIS data - Part 2: Case studies and trends of sea ice albedo and melt ponds in the Arctic for years 2002-2011
}

\author{
L. Istomina ${ }^{1}$, G. Heygster ${ }^{1}$, M. Huntemann ${ }^{1}$, H. Marks ${ }^{1}$, C. Melsheimer ${ }^{1}$, E. Zege ${ }^{2}$, A. Malinka ${ }^{2}$, A. Prikhach ${ }^{2}$, and \\ I. Katsev ${ }^{2}$ \\ ${ }^{1}$ Institute of Environmental Physics, University of Bremen, Bremen, Germany \\ ${ }^{2}$ B. I. Stepanov Institute of Physics, National Academy of Sciences of Belarus, Minsk, Belarus
}

Correspondence to: L. Istomina (lora@iup.physik.uni-bremen.de)

Received: 5 September 2014 - Published in The Cryosphere Discuss.: 15 October 2014

Revised: 11 July 2015 - Accepted: 27 July 2015 - Published: 12 August 2015

\begin{abstract}
The spatial and temporal dynamics of melt ponds and sea ice albedo contain information on the current state and the trend of the climate of the Arctic region. This publication presents a study on melt pond fraction (MPF) and sea ice albedo spatial and temporal dynamics obtained with the Melt Pond Detection (MPD) retrieval scheme for the Medium Resolution Imaging Spectrometer (MERIS) satellite data. This study compares sea ice albedo and MPF to surface air temperature reanalysis data, compares MPF retrieved from the Moderate Resolution Imaging Spectroradiometer (MODIS), and examines albedo and MPF trends. Weekly averages of MPF for 2007 and 2011 showed different MPF dynamics while summer sea ice minimum was similar for both years. The gridded MPF and albedo products compare well to independent reanalysis temperature data and show melt onset when the temperature gets above zero; however MPD shows an offset at low MPFs of about $10 \%$ most probably due to unscreened high clouds. Weekly averaged trends show pronounced dynamics of both, MPF and albedo: a negative MPF trend in the East Siberian Sea and a positive MPF trend around the Queen Elizabeth Islands. The negative MPF trend appears due to a change of the absolute MPF value in its peak, whereas the positive MPF trend is created by the earlier melt onset, with the peak MPF values unchanged. The MPF dynamics in the East Siberian Sea could indicate a temporal change of ice type prevailing in the region, as opposed to the Queen Elizabeth Islands, where MPF dynamics react to an earlier seasonal onset of melt.
\end{abstract}

\section{Introduction}

In the last few decades, the sea ice extent (defined as the total area with at least $15 \%$ of ice cover) and area of multiyear ice (MYI) has been declining at even faster rate than that of the total perennial ice (Comiso, 2012). This tendency of the sea ice towards thinner and younger ice has a strong impact on the energy balance of the system atmosphere-sea ice-ocean (Perovich et al., 2011; Wang et al., 2014), where $96 \%$ of the total annual solar heat input through sea ice occurs during the melt season from May to August (Arndt and Nicolaus, 2014). The above-mentioned effects are of importance within the context of a changing Arctic due to the sensitivity of the regional climate balance and its importance for the global climate (Shindell and Faluvegi, 2009).

The extent of the Arctic sea ice cover has a pronounced seasonal cycle with the maximum typically in March (in February in 2015) and the minimum in September. The main feature of the sea ice in summer is the presence of melt ponds. Knowing their spatial and temporal dynamics during the melt season and over several years can help improve understanding of the current state and trends of the energy balance in the region. The sea ice extent has been showing a general declining trend ever since the beginning of continuous satellite observations in the late 1970s. This decline has been stronger for the September minimum than for the March maximum (Cavalieri and Parkinson, 2012; Stroeve et al., 2011). The decline of the minimum sea ice extent has become very significant since 2007: in September 2007, the minimum sea ice extent of 4.15 million $\mathrm{km}^{2}$ was about $39 \%$ 
below the average minimum of 1981-2000, and in 2012 the minimum ( 3.41 million $\mathrm{km}^{2}$ ) was $49 \%$ below the $1981-2000$ average (Perovich et al., 2012). While the minima of Arctic sea ice extent were less dramatic in the years following 2007, it has to be noted that all minima after 2007 were below all yearly minima observed before 2007 (since beginning of satellite observations). What is the role of melt ponds in the above-mentioned yearly dynamics of the sea ice cover? The clear connection between the area of melt ponds in spring and sea ice extent during the sea ice minimum in autumn is highlighted in Schröder et al. (2014).

The temporal dynamics of melt can be subdivided into four stages (Eicken et al., 2002). Stage 1 occurs after the onset of positive air temperatures and is characterized by widespread ponding and lateral melt water flow. During stage 2 both the surface albedo and melt pond fraction (MPF) decrease due to removal of snow cover and due to pond drainage. During stage 3 , as the meltwater penetrates deeper into the ice, the pond coverage continues to evolve and MPF to grow. Stage 4 corresponds to freeze-up. This publication is dedicated to the application of the algorithm to retrieve MPF and sea ice albedo described and validated in the companion publications (Istomina et al., 2015; Zege et al., 2015). As the Melt Pond Detection (MPD) retrieval does not see separate ponds, but detects the spectral signature of melt ponds in the measured top-of-atmosphere signal, the retrieved MPF dynamics will somewhat deviate from above-mentioned stages of melt observed in the field. The reason for this deviation is the ambiguity of the top-of-atmosphere signal, where e.g. the spectrum of melting sea ice (before stage 1) can be represented as a linear mixture of pond spectrum and non-melting ice spectrum, as can be seen from field spectra in e.g. Istomina et al. (2013). The problem is addressed in MPD by setting boundary conditions on optical parameters given in Eq. (18) in Zege et al. (2015). However, as the MPD uses only a limited amount of spectral bands in the visible (VIS) and near infrared (NIR) surfaces which are similar in these channels may all be retrieved as MPF, e.g. submerged ice, blue ice and water-saturated ice without yet actual meltwater on it. This may introduce a bias in the MPF product (not sea ice albedo); however, it does not imply limitations on the usage of the MPD product for the studies of radiative balance and global circulation models. Another source of bias of the MPD product are the unscreened thin clouds.

All available Medium Resolution Imaging Spectrometer (MERIS) reduced resolution data for the Arctic summers from 2002 to 2011 are processed and compiled in lower resolution in daily and weekly averages to increase the coverage and quality of the data. As the temporal evolution of the MPF and the surface albedo is naturally correlated with the evolution in air temperature at the surface, a comparison to National Centers for Environmental Prediction (NCEP) reanalysis temperature data for various ice types was performed to check the performance of the algorithm. This has been done for extended periods of time (over the whole summer); also, in the context of the above-mentioned connection of the MPF and sea ice extent, the MPF dynamics have been studied for the 2 years 2007 and 2011 and also compared to the data by Rösel and Kaleschke (2012) for selected cases. The performed comparisons showed clear agreement both to reanalysis data and to the MPF by Rösel and Kaleschke (2012).

The manuscript is structured as follows: Sect. 2 is dedicated to the comparison of the MPF and albedo data to the reanalysis air temperature for various locations. Global applications of the MPD algorithms over the whole MERIS data set (2002-2011) are given in Sect. 3. There the weekly averages for 2007 and 2011 are analyzed (Sect. 3.1); for these cases a comparison to another MPF retrieval is performed (Sect. 3.2) and MPF (Sect. 3.3) and sea ice albedo trends (Sect. 3.4) are presented. The conclusions are given in Sect. 4.

\section{Comparisons between surface air temperature and time series of MPF and albedo: case studies of FYI and MYI}

The processed swath MERIS Level $1 \mathrm{~b}$ data obtained with the MPD algorithm as described in the companion publications (Istomina et al., 2015; Zege et al., 2015) have been gridded daily into the $12.5 \mathrm{~km}$ polar stereographic grid (the so-called National Snow and Ice Data Center (NSIDC) grid) with the criterion of more than $50 \%$ valid pixels (both spatially and temporally) within a grid cell to produce a valid grid cell. The standard deviation of such a mixed spatial and temporal average is also provided. Thus, the resulting NetCDF file contains four data sets: MPF, broadband albedo and their standard deviations (STDs). On average, there were around 13 overflights per day, with the density of overlapping swaths highest at about $80^{\circ} \mathrm{N}$ latitude. Even from a single overflight, there are at least 100 up to about 1000 data points for averaging into a single grid cell. Assuming a stable retrieval and low variations within a single day, the STD gives information about the spatial variation of MPF and broadband albedo within the grid cell. This kind of averaging does not provide a guarantee of a valid data point for every single day and grid point. The gridding method with a threshold on the amount of cloud-free pixels allowed to form a valid grid cell assists with cloud screening because it does not allow partly screened out clouds or potentially unscreened cloud edges to appear in the end product. However, since the Arctic is one of the most cloud-covered regions with up to $80 \%$ cloud cover throughout the year (Serreze and Barry, 2005), some of unscreened clouds will still affect the gridded product. The amplitude of this effect tends to be the greatest (up to $15 \%$ MPF bias) before melt onset as it is the most challenging to separate clouds and bright snow/sea ice. Later in the season the surface becomes darker due to melt, which aids the cloud screening, and the bias in MPF and albedo introduced by unscreened clouds decreases. 
The weekly resolution has been obtained by averaging the gridded daily product. As in the case of daily resolution, a weekly averaged grid cell is obtained from no less than $50 \%$ of valid (cloud-free) pixels. Should a given grid cell contain more than $50 \%$ of invalid pixels, it is assigned not a number value. No weight or threshold on STDs is applied. The resulting STD is then written into the resulting NetCDF file together with the averaged value for the broadband albedo and MPF.

These weekly averages have a much higher data density since there is a higher probability for the satellite to observe cloud-free areas within 1 week than it is the case for 1 day.

For this study, the daily averaged product was taken in the area $75^{\circ} \mathrm{N}, 155^{\circ} \mathrm{W}$ (Beaufort Sea) and $84.5^{\circ} \mathrm{N}, 35^{\circ} \mathrm{W}$ (North Greenland) and it was compared to the time sequence of daily averaged air temperature at the surface (0.995 sigma level) from NCEP reanalysis data (Kalnay et al., 1996). The difference between melt evolution in the selected location is mainly that melt onset happens about a month earlier in lower latitudes: beginning of June on FYI as opposed to beginning of July for MYI. Then, due to FYI roughness being much less than that of MYI, the maximum MPF on FYI can be about 4 times higher than that on MYI (maximum melt 0.2 on MYI as opposed to up to 0.8 on FYI, Fig. 1 in Istomina et al., 2015). While the melt onset occurs rapidly on both ice types, the later stage of melt - drainage of melt ponds - happens much sooner on FYI than on MYI. On MYI, this stage is generally substituted with MPF decrease due to freezing and snowfall events. One more difference between the two chosen locations is the sea ice concentration: for the MYI, the ice concentration stays very high throughout the whole summer, whereas for the FYI region, the effect of ice concentration and also ice drift (in the swath data for consecutive days separate floes and their drift is clearly visible) can affect the time sequence analysis, affecting the noisiness of the retrieved values.

Overall, the comparison of the retrieved MPFs and albedos to the surface air temperature (Fig. 2) shows a clear connection during the melt onset: as soon as air temperature assumes constantly positive values, sea ice albedo drops down and MPF increases abruptly. For both FYI and MYI, the maximum MPF is around 0.35 , with melt onset happening in the beginning of June for FYI and beginning of July for MYI. This corresponds to the knowledge about melt onset and dynamics from field measurements (Fig. 1 in Istomina et al., 2015). The evolution of melt on MYI follows the air temperature dynamics and goes on till first snowfalls and freezing temperatures around mid August. The FYI region, however, is closer to the ice edge and therefore features a greater range of ice concentrations within the study area. As a result, the corresponding curve appears noisier and interrupts with the area becoming ice free starting 1 August. For periods before melt onset, the retrieved MPFs range from 0 to $10-15 \%$ with relatively high albedos; both might be the effect of unscreened clouds which tend to increase retrieved pond frac-

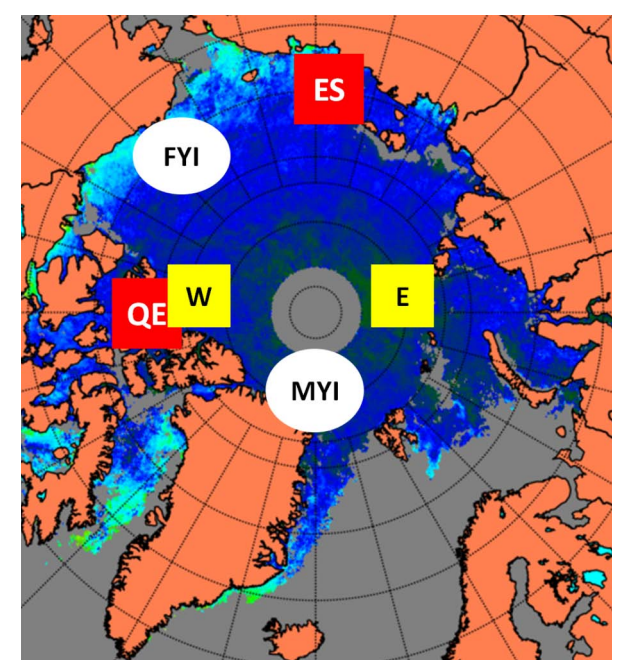

Figure 1. Schematic depiction of the case study locations (the size of the labels does not correspond to the real size of the studied area, see text for area sizes). White circles depict locations for the time sequence analysis in summer 2009, in the Beaufort Sea, FYI (red curves in Fig. 2) and North Greenland, MYI (blue curves in Fig. 2). Yellow squares show locations for two sites in both 2007 and 2011, namely in Barents Sea (E) and north to the Queen Elizabeth Islands (W) (Fig. 5). Red squares depict the locations of two sites between the Queen Elizabeth Islands (Fig. 10) and in the East Siberian Sea (Fig. 9), where the MPF temporal behaviour was compared for years 2002-2011.

tion in case of small true pond fraction and decrease it in case of high true pond fractions. The difference of the sea ice type is also visible in the albedo values before the melt onset (Fig. 2): higher albedo of $90 \%$ for MYI region and lower albedo of about $80 \%$ ) for the coastal region of Beaufort Sea. For MPF before melt onset, the effect of subpixel ice floes and greater open water fraction as compared to the MYI region may have caused the difference in MPF offset with respect to expected value near zero before melt (Fig. 2).

\section{Temporal and spatial analysis over the whole MERIS data set}

This chapter presents the main highlights of the processed MERIS data for 2002-2011. Weekly averages have been used for this study due to better data coverage; therefore the shown trends are produced with the weekly resolution.

The most striking and characteristic stage of the melt season is the melt onset and the first stage of melt evolution. Such dynamics are ice type specific, e.g. on FYI this is the rapid melt pond formation followed by a rapid drainage, during which the MPF changes drastically up and down within a scale of days to weeks. MYI features later (starts in July) and slower melt onset, less extreme pond fractions with the absence of rapid melt evolution stages. The pond fractions in the melt maximum on MYI are close to pond fractions of the 


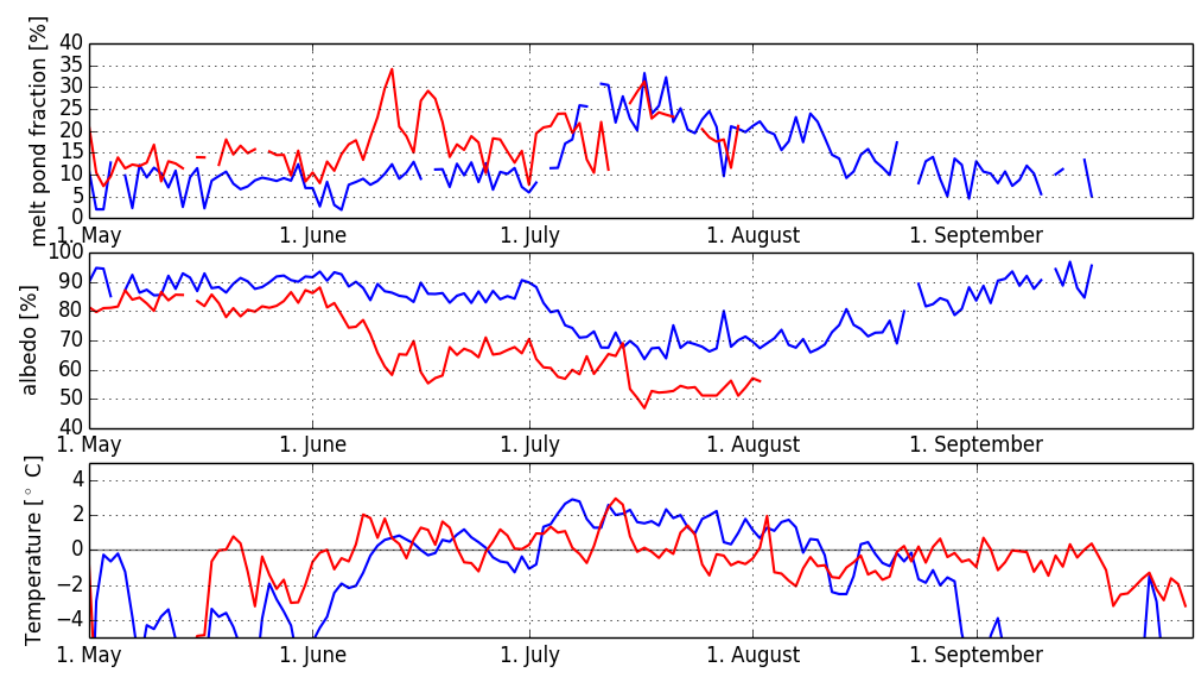

Figure 2. Time sequence of MPF, broadband albedo and NCEP air temperature at the surface for two regions: FYI area in Beaufort Sea near Barrow $\left(75^{\circ} \mathrm{N}, 155^{\circ} \mathrm{W}\right.$, shown in red) and MYI area around North Greenland $\left(84.5^{\circ} \mathrm{N}, 35^{\circ} \mathrm{W}\right.$, shown in blue) May to September 2009. Locations are shown in Fig. 1 with white circles tagged "FYI" and "MYI", respectively. The albedo and MPF curves in the FYI area are interrupted as the area becomes completely ice free on the 1st of August 2009.

melt evolution (after melt onset and drainage) on FYI. Thus, the difference of MPF on FYI and MYI is most prominent in June. Therefore in this work we study the temporal variation of MPF and albedo for June of each year of the available MERIS data set.

\subsection{Weekly averages of June 2007 and 2011: how the record ice minimum in 2007 started}

It is interesting to compare the evolution of melt ponds right after the onset of melt for the record sea ice minimum in 2007 and a similar one by the ice minimum extent year 2011, to see how the patterns of melt changed within these 5 years to reach the same resulting ice extent during the sea ice minimum. In Fig. 3 the evolution of the MPFs from the last 2 weeks of May up to first 2 weeks of September 2007 and 2011 is shown. Both the onset of melt and melt stage 1 occur in the fourth week of May at the shore of Beaufort Sea (2007) and East Siberian Sea (2011).

The melt stage 1 during the first week of June has much more local character in 2011 than in 2007, being centred near point Barrow and the shore of Beaufort Sea, as opposed to 2007 when the melt onset began already at a more global scale. The second week of June 2007 featured drastic melt which corresponds to the last phase of melt stage 1 with MPF values up to about $50 \%$ in the Beaufort Sea and the western part of the FYI covered Arctic Ocean (top row panels in Fig. 4), whereas in 2011 the situation was more or less stable relative to the first week of June.

\subsection{Comparison to MPF from MODIS data (Rösel et al., 2012)}

For this comparison, two examples presented in Rösel and Kaleschke (2012) are taken: 8-day composites starting on 18 June 2007 and 18 June 2011. These are the cases of prominent difference in melt pond patterns in 2007 and 2011. In order to compare the two data sets, the 8-day composites from MODIS (pond fraction relative to ice area) available at the web page of University of Hamburg: http://icdc.zmaw.de/ arctic_meltponds.html?\&L=1 have been converted into pond fraction relative to pixel area using the provided ice concentration. Corresponding 8-day averages have been created from the MPD daily gridded data. The selection of valid grid cells in the data set by Rösel et al. (2012) is the following: not less than $50 \%$ valid pixels for a valid grid cell, ice concentration greater than $25 \%$, STD of MPF less than $15 \%$. The comparison plot is shown in Fig. 6. It is apparent that for the 18 June 2007 both data sets show similar spatial patterns with higher MPF between the Queen Elizabeth Islands and Beaufort Sea, and lower MPF in the MYI region north to Greenland and eastern part of the Arctic Ocean. This pond fraction distribution seems plausible when considering the date of observation, before melt onset in the MYI region, and such a spatial distribution is confirmed by both algorithms. The MPF values slightly differ in amplitude (note the distribution of higher and lower MPF in both data sets e.g. in the Beaufort Sea). The primary reason for this difference is likely the contrast in cloud screening methods between the two data sets, with MODIS much better suited to cloud screening over snow, resulting in differences in the fraction of unscreened clouds between both data sets. The second reason is the dif- 

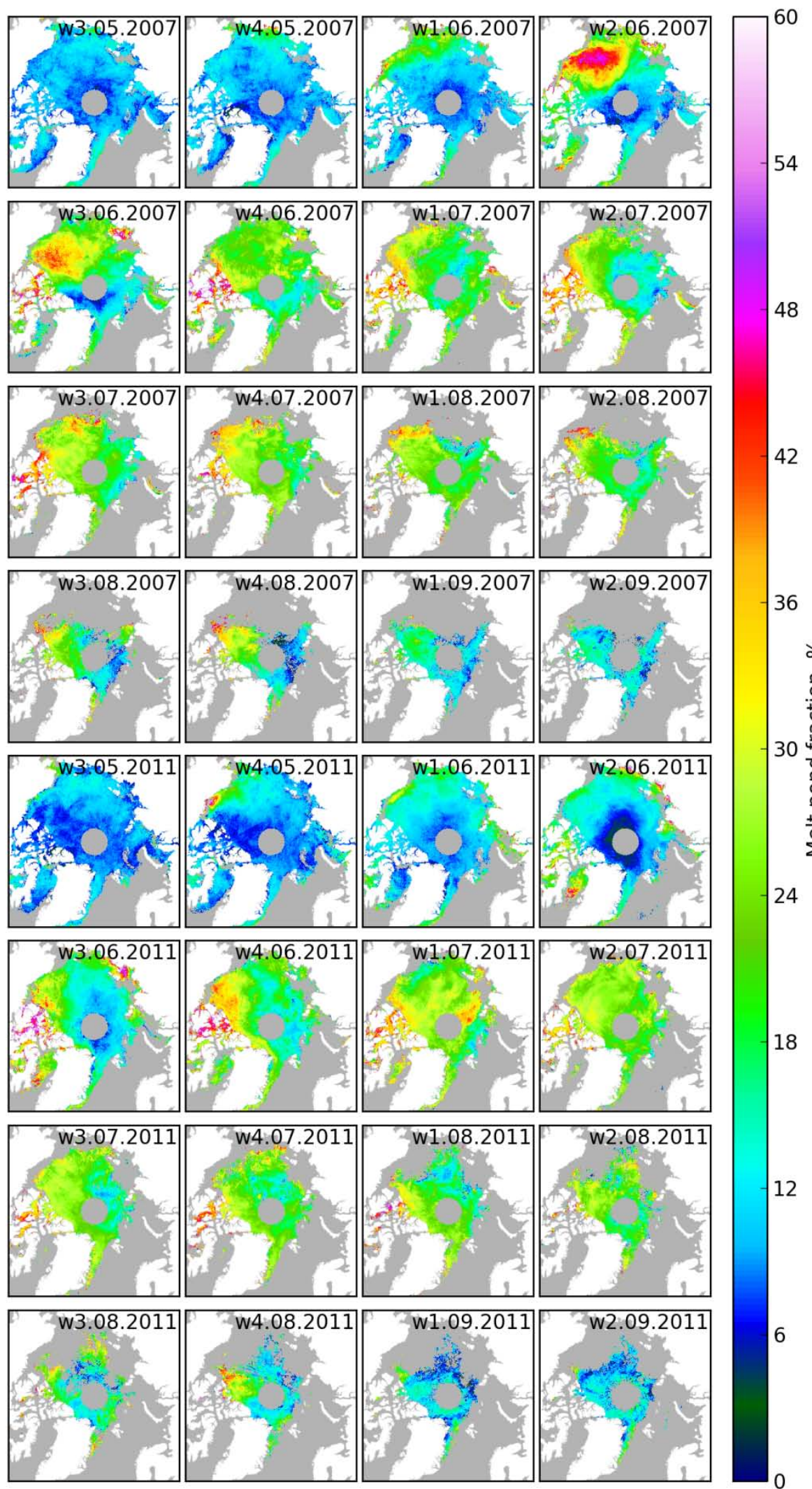

Figure 3. Retrieved weekly averaged MPF for summer 2007 and 2011. 

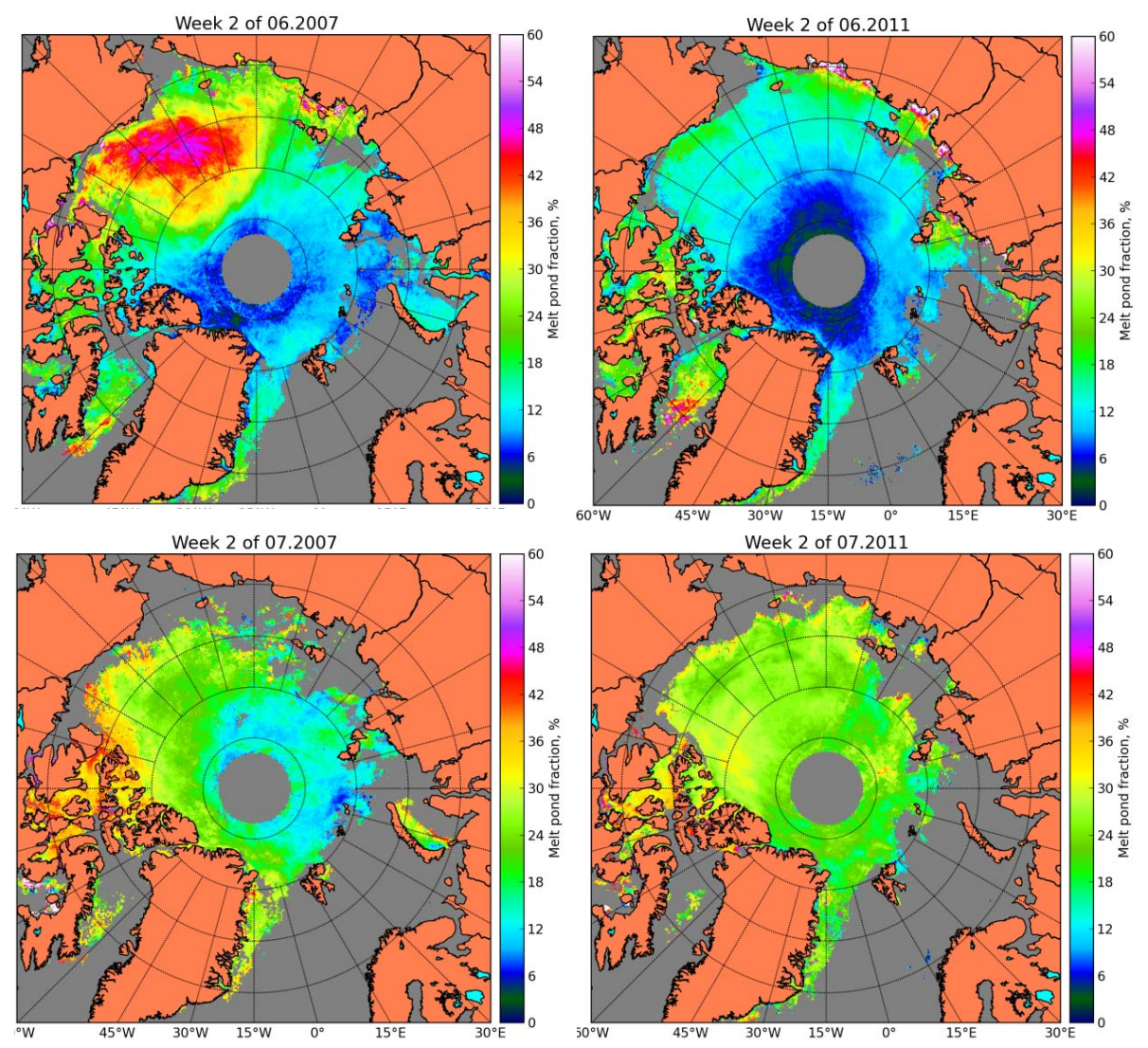

Figure 4. Main differences of weekly MPF averages 2007 and 2011 (Fig. 3). Comparison of the weekly average pond fraction for the second week of June 2007 and 2011 (top row panels, left and right correspondingly) and for the second week of July 2007 and 2011 (bottom row panels, left and right correspondingly). Note the drastic melt onset in the 2nd week of June 2007, but lower MPFs in the 2nd week of July 2007 compared to 2011.

ferent averaging method, with data by Rösel et al. (2012) being produced as a composite (best or most characteristic observation within the period), whereas MPD data is obtained by unweighted averaging. And finally the third reason for the difference is the positive $8 \%$ offset of the data set by Rösel et al. (2012) as provided in the "Data quality" section at the data source http://icdc.zmaw.de/arctic_meltponds.html?\&L=1. It is unclear whether this bias is constant over the whole range of MPFs and if it is possible to correct for it. Mäkynen et al. (2014) suggest that the bias stems from possibly inaccurate assumption about sea ice optical properties, which would mean that the bias varies not only with MPF, but also with weather conditions and location in the Arctic ocean.

The second row of Fig. 6 shows the same comparison, but for 18 June 2011. Here again, both algorithms agree on the spatial distribution of the melt ponds, with slight differences in the amplitude, and thus confirm the plausibility of results presented both in Sect. 3.1 and in Rösel and Kaleschke (2012).

\subsection{Spatial trends of MPFs for the Arctic Ocean over the whole MERIS data set (2002-2011)}

As seen from the comparison to in situ data and reanalysis temperature data, the MPD retrieval is affected by unscreened high thin clouds, to which none of the available cloud filters are sensitive but which affect the retrieved MPF and albedo because clouds tend to increase the albedo/decrease pond fraction for areas of high true MPF and increase MPF/decrease albedo for areas of no or little melt. This produces an offset at the low MPFs and is mainly visible at the beginning of the melt season. It affects also the maximum reachable MPFs at the peak of the melt and the minimum MPFs before and after the season. The performance of the algorithm is compromised during the end of the melt season due to the presence of over-frozen, snow covered or melted through melt ponds.

Nevertheless, for the MERIS data the temporal dynamics of the retrieved quantities compares well with the NCEP surface air temperature data and the weekly averages show pronounced spatial variability of the retrieved pond fractions for different years which cannot be explained by thin cloud 

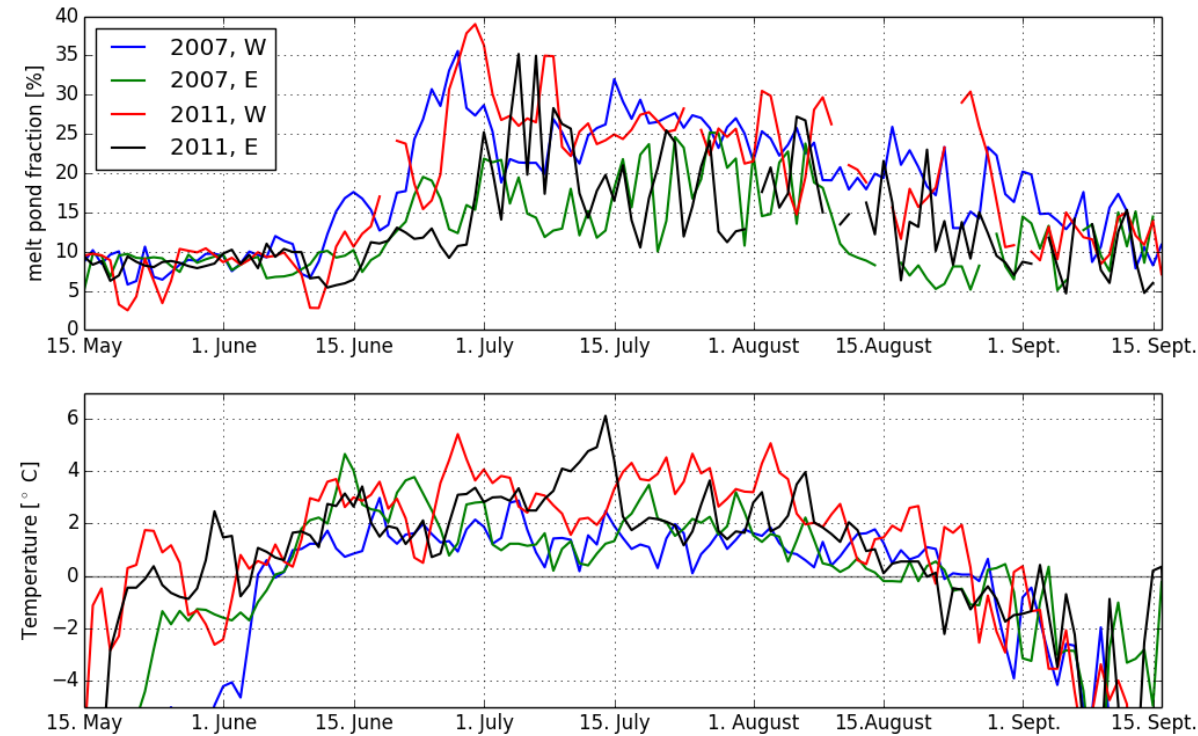

Figure 5. Daily averages of MPF (top panel) and NCEP air temperature at the surface (bottom panel) for two locations with the similar melt dynamics ("reference") and diverse melt dynamics ("characteristic"): reference location to the north to the Queen Elizabeth Islands, $83^{\circ} \mathrm{N}$, $110^{\circ} \mathrm{W}$ (tag "W" in the legend), 2007 (blue curves) and 2011 (red curves) and characteristic location in the Barents Sea, $85^{\circ} \mathrm{N}, 65^{\circ} \mathrm{E}$ (tag "E" in the legend), 2007 (green curves) and 2011 (black curves). Locations are shown in Fig. 1.
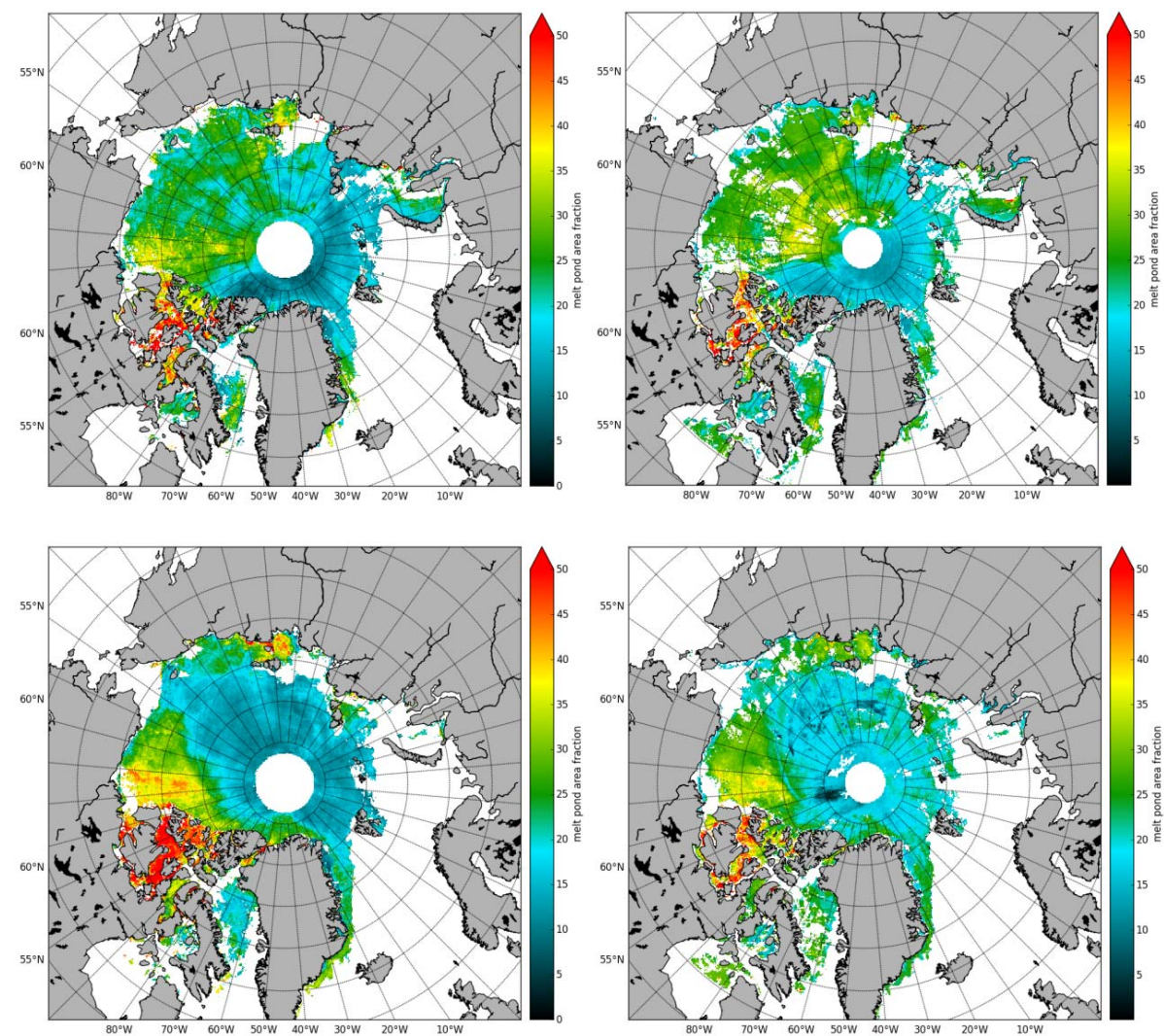

Figure 6. Comparison of the MPD MPF (8-day average, left column panels) to the MPF from (Rösel and Kaleschke, 2012) (8-day composite, right column) for 18 June 2007 (top row panels) and 18 June 2011 (bottom row panels). 

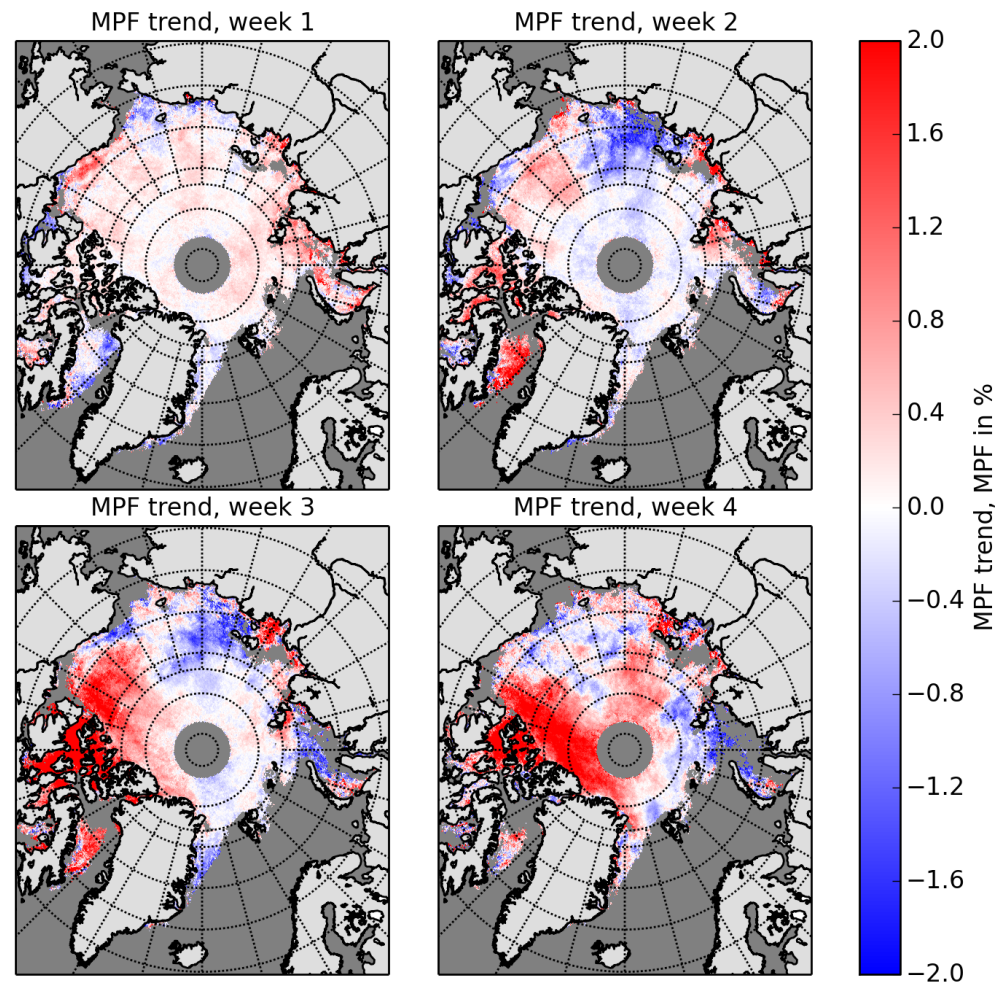

Figure 7. Melt pond fraction trends (trend in MPF \%) for the 4 weeks of June for the whole investigation period 2002-2011.
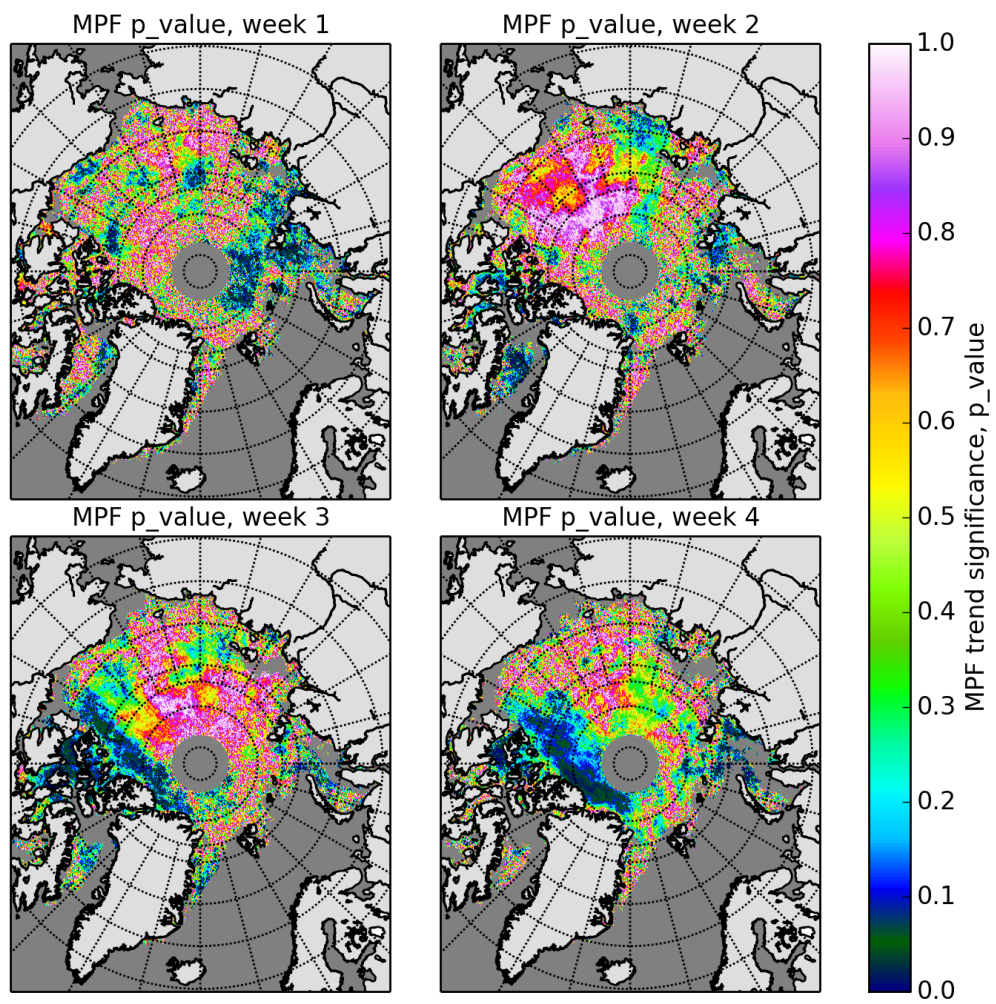

Figure 8. $P$ values for the weekly MPF trends (see Fig. 7). 


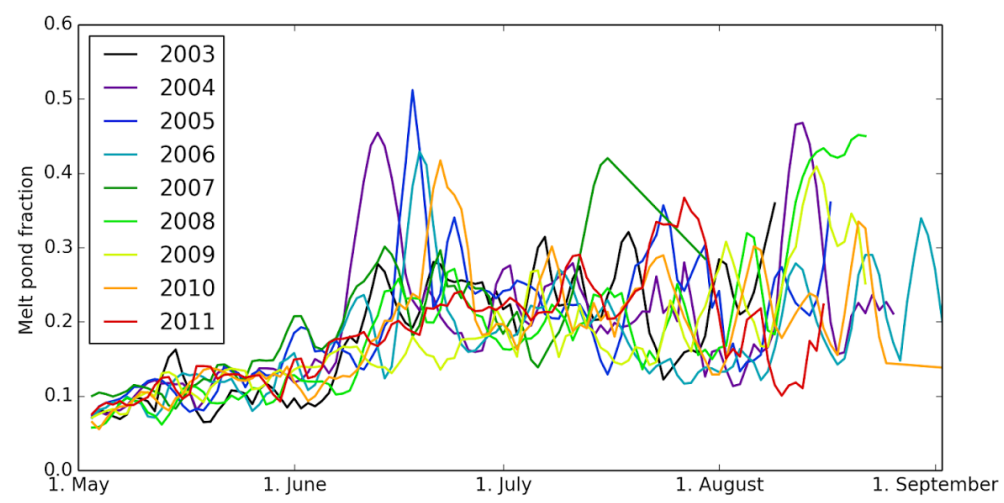

Figure 9. Time sequence of MPF for the studied years for the area of negative MPF trend in the East Siberian Sea $\left(74^{\circ} \mathrm{N}, 160^{\circ} \mathrm{E}\right.$, marked with the red square "ES" in Fig. 1). In the 2nd-3rd week of June the MPF in the earlier years of the MERIS data set reached high (up to 0.5) peak values as the melt onset started, which is typical for the first year ice. In the later years, however, the behaviour of the MPF more resembles that of the MYI: no rapid melt onset, lower peak values of MPF. Running mean with window size 3 has been applied to the data.

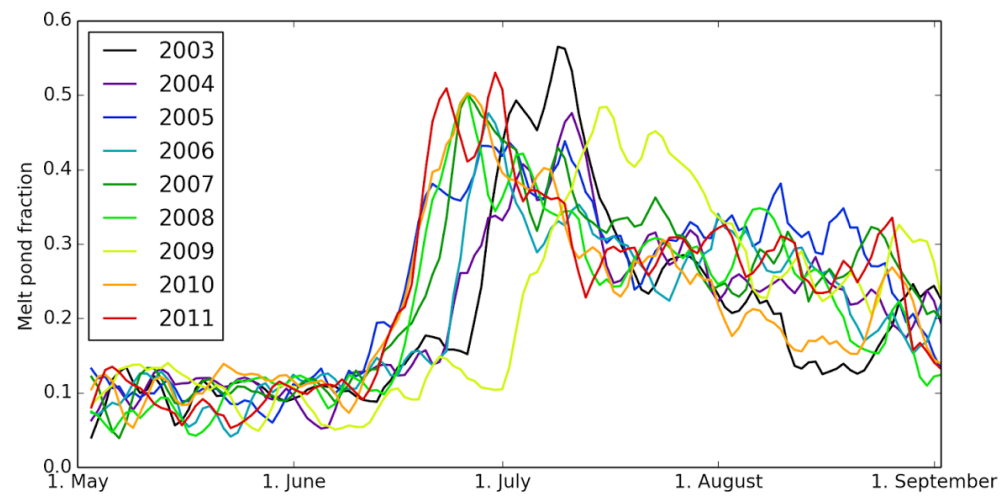

Figure 10. Time sequence of MPF for the studied years for the area of positive MPF trend in the Queen Elizabeth Islands $\left(78^{\circ} \mathrm{N}, 108^{\circ} \mathrm{E}\right.$, marked with the red square "QE" in Fig. 1). In the 3rd-4th week of June the MPF in the earlier years of the MERIS data set reached peak values later in the summer as compared to later years, and melt onset in the later year happens earlier than before. Running mean with window size 3 has been applied to the data.

cover. This gives us the possibility to study the trends of the retrieved quantities as a potential systematic offset due to clouds would be cancelled out and only the variability of the true value shows up in the trend (Fig. 7). The trend significance given by the map of the MPF trend $p$ value (Fig. 8) confirms this finding: the strongest positive or negative trends are the most significant ones with the $p$ value of about $0.05-$ 0.1 . Given the small size of the studied sample (10 points), the statistically significant $p$ value is expected to be greater than that of the larger samples. Therefore the $p$ values obtained here can be used to select the trend candidates. One more criterion that supports the statistical significance of the discovered trends is the spatial continuity of the $p$ value that suggests the non-random nature of the effect.

There is no trend for the first week of June throughout the years (Fig. 7), except for a slight positive trend of MPF near Point Barrow. This feature disappears for the second week, and a positive trend of 1-2\% during the early melt season is found near the Queen Elizabeth Islands. This trend re- mains until the end of June. Explanation for this finding is not the increase in the absolute value of the MPF, but rather the melt onset shifting towards spring in these areas throughout the MERIS data set (Fig. 10). A negative trend in the East Siberian Sea has yet to be explained: either it is the opposite temporal shift of melt evolution towards summer, or a shift of melt evolution towards spring with e.g. drainage phase of melt observed instead of maximum melt, or a fluctuation in the weather conditions or in the ice type in the area within the studied years. It is important to understand that the trend of the MPF can as likely occur due to temporal shift of the melt process towards spring or autumn, as well as change of maximum possible pond fraction due to ice type change. The maximum and average MPFs depend not only on the air temperature, but also on the sea ice roughness on various scales and other ice properties (Polashenski et al., 2012), so an increasing air temperature trend in the area would not necessarily produce an increasing MPF trend. The time sequence of MPF for the studied years for the location of interest in the 


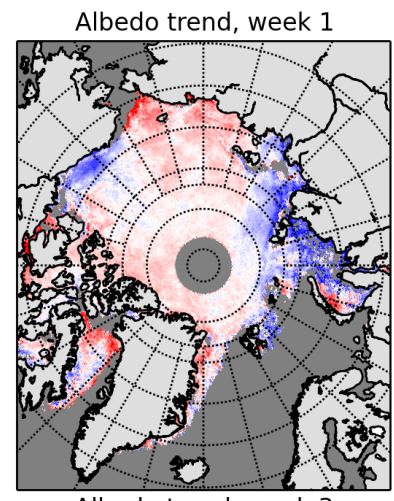

Albedo trend, week 3

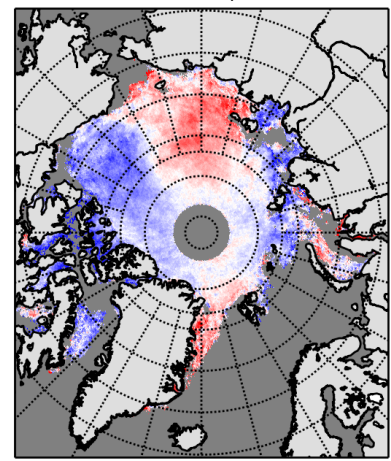

Albedo trend, week 2

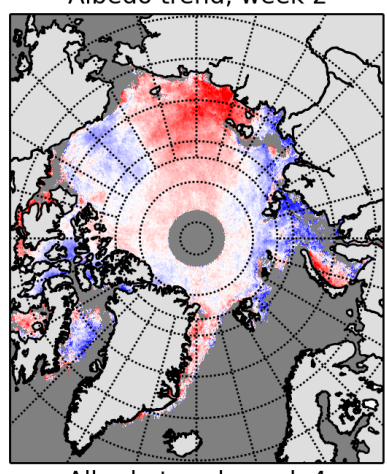

Albedo trend, week 4

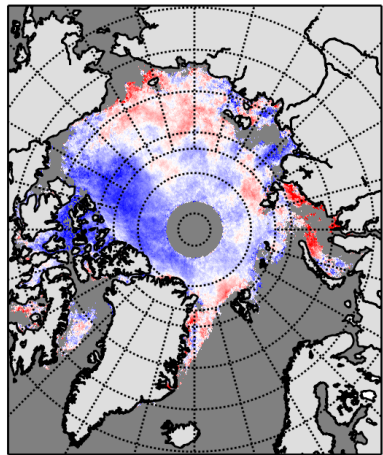

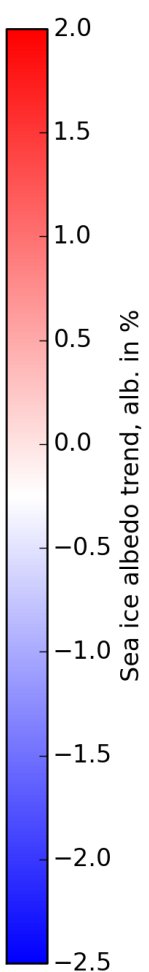

Figure 11. Broadband sea ice albedo trends (trend in albedo \%) for the 4 weeks of June for the whole investigation period $2002-2011$.
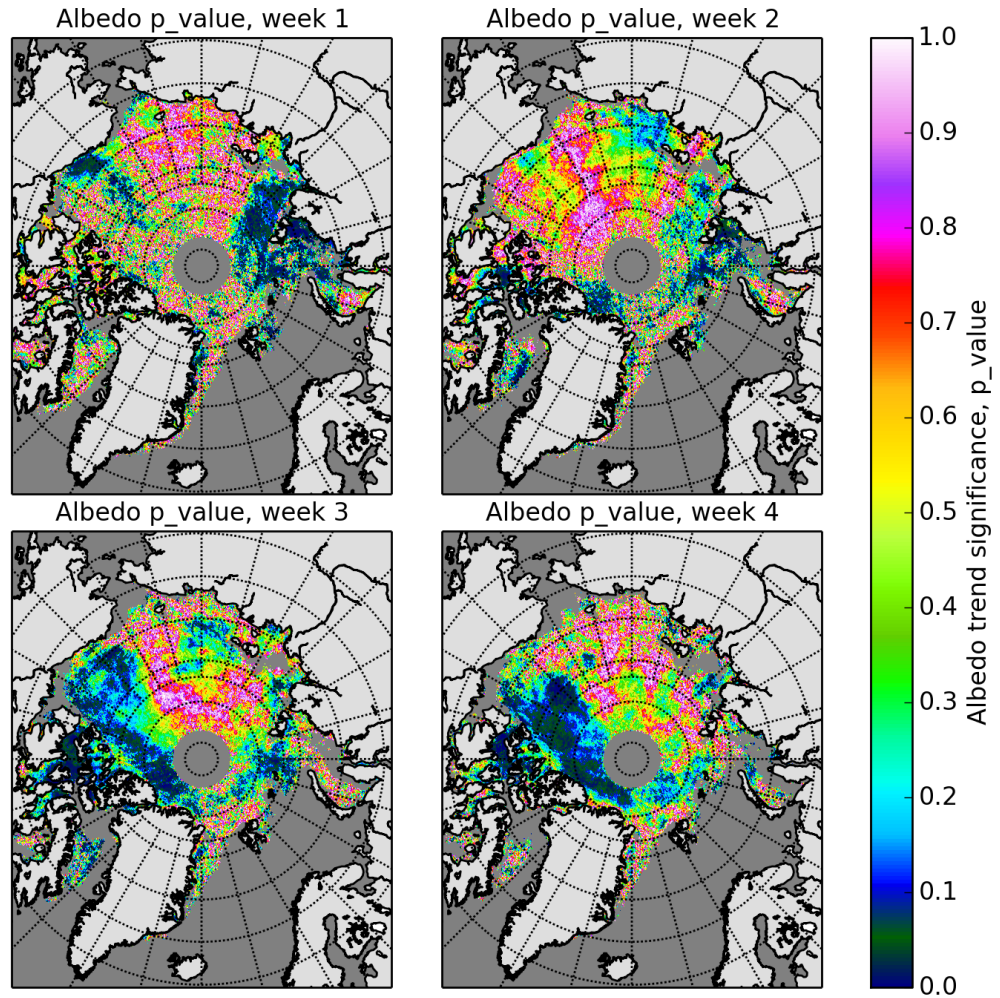

Figure 12. $P$ values for the weekly broadband albedo trends (see Fig. 11). 
East Siberian Sea $\left(74^{\circ} \mathrm{N}, 160^{\circ} \mathrm{E}\right.$ averaged $50 \mathrm{~km}$ around the point) is shown in Fig. 9.

The MPF curves for different years hardly show any temporal shift, but display a change of absolute MPF and of temporal behaviour of the melt evolution, which is an indication of an ice type change from FYI to MYI. E.g. the curve corresponding to 2011 in Fig. 9 (red curve) shows a clear MYI MPF dynamics. The presence of MYI in the area is confirmed by analyzing the maps of ice concentration for the autumn before in the region of interest (not shown here, for details see AMSR-E ice concentration maps provided by Uni Bremen, http://www.iup.uni-bremen. de:8084/databrowser.html). At the same time, a similar plot (Fig. 10) for the Queen Elizabeth Islands $(50 \mathrm{~km}$ around $78^{\circ} \mathrm{N}, 108^{\circ} \mathrm{W}$ ) displays the exact opposite: the peak of MPF for the melt onset shifts towards spring in the later years of the MERIS data set, whereas the absolute value of the MPF peak stays the same. This is the sign of warm air masses appearing earlier in the summer than before, producing the positive MPF trend for the area.

The MPF trend for the 4th week of June features earlier melt onset in the MYI regions and further melt overall in the Arctic ocean with occasional hints of longitudinal oscillations, e.g. in week 4 of June (Fig. 7).

\subsection{Spatial trends of broadband sea ice albedo for the Arctic Ocean over the whole MERIS data set (2002-2011)}

The MPF and the broadband albedo of the pixel are joint products, i.e. an increasing trend for MPF gives a decreasing trend of the albedo. A decreasing albedo trend around the Queen Elizabeth Islands and increasing trend in the East Siberian Sea (see Fig. 11) correspond well to dynamics of the apparent MPF weekly trends (Fig. 7) and are confirmed by low $p$ values (Fig. 12). The slight differences in spatial patterns of albedo and MPF trends can be explained by different sensitivity of both retrievals to different ice types and their respective optical properties: the albedo retrieval translates the change of ice reflectance into the albedo of the pixel, whereas the MPF retrieval only retrieves MPF. The albedo trend significance which a displays similar spatial pattern as the significance of the MPF trend (Fig. 8) is shown in Fig. 12. As can be seen from the albedo trend significance, the remaining areas did not show clear albedo trend within the studied period of time.

\section{Conclusions}

This publication presents a detailed analysis of the MPD product (Istomina et al., 2015; Zege et al., 2015) consisting of a comparison to reanalysis air surface temperatures, detailed analysis of weekly averages for 2007 and 2011 (which both showed different dynamics of MPF, but resulted in similar minimum sea ice extent), a comparison to the data by Rösel et al. (2012), and an analysis of albedo and MPF trends. The gridded products compare well to independent reanalysis temperature data and show melt onset when the temperature gets above zero degrees Celsius (Fig. 2); however MPD results show an offset at low MPF of about $10 \%$ most probably due to unscreened high clouds. This makes the application of the MPD algorithm to a sensor with a more precise cloud mask desirable (Visible Infrared Imaging Radiometer Suite (VIIRS) onboard Suomi NPP or Ocean Land Colour Instrument (OLCI) onboard Sentinel3). Though absolute daily values of MPF and albedo may be affected by unscreened clouds, relative MPF and albedo differences through the temporal axis are significant and the temporal MPF dynamics correspond to that observed in the field for FYI and MYI (Fig. 2). This is also applicable to weekly averages based on analysis of MPF behaviour in 2007 and 2011 (Figs. 3 and 4) and on the comparison of the MPD product to data by Rösel et al. (2012) (Fig. 6). Thus, the MPD products are suitable for analyzing temporal and spatial dynamics of MPF and sea ice albedo.

Weekly averaged trends show pronounced dynamics of both MPF and albedo: a negative MPF trend in the East Siberian Sea connected to a change of absolute MPF value in its peak but no temporal shift, a positive MPF trend around the Queen Elizabeth Islands connected to the earlier melt onset but with peak MPF values staying the same (Figs. 7, 9 and 10). The MPF dynamics in the East Siberian Sea could indicate a change of ice type prevailing in the region, as opposed to the Queen Elizabeth Island, where the MPF dynamics react to earlier onset of melt. This will be analyzed further in a follow-up publication.

Acknowledgements. NCEP Reanalysis data provided by the NOAA/OAR/ESRL PSD, Boulder, Colorado, USA, from their web site at http://www.esrl.noaa.gov/psd/.

Arctic melt pond cover fractions were obtained for June 2007 and 2011 from the Integrated Climate Data Center (ICDC, http: //icdc.zmaw,de/), University of Hamburg, Hamburg, Germany, March 2015.

The authors are grateful to the two anonymous reviewers and the editor H. Eicken for their effort and valuable comments on the manuscript.

This work has been funded as a part of EU project SIDARUS.

The article processing charges for this open-access publication were covered by the University of Bremen.

Edited by: H. Eicken 


\section{References}

Arndt, S. and Nicolaus, M.: Seasonal cycle and long-term trend of solar energy fluxes through Arctic sea ice, The Cryosphere, 8, 2219-2233, doi:10.5194/tc-8-2219-2014, 2014.

Cavalieri, D. J. and Parkinson, C. L.: Arctic sea ice variability and trends, 1979-2010, The Cryosphere, 6, 881-889, doi:10.5194/tc6-881-2012, 2012.

Comiso, J. C.: Large Decadal Decline of the Arctic Multiyear Ice Cover, J. Climate, 25, 1176-1193, doi:10.1175/JCLI-D-11$00113.1,2012$.

Eicken, H., Krouse, H. R., Kadko, D., and Perovich, D. K.: Tracer studies of pathways and rates of meltwater transport through Arctic summer sea ice, J. Geophys. Res., 107, 8046, doi:10.1029/2000JC000583, 2002.

Istomina, L., Nicolaus, M., and Perovich, D.: Spectral albedo of sea ice and melt ponds measured during POLARSTERN cruise ARK XXII/3 (IceArc) in 2012, PANGAEA Dataset, Institut für Umweltphysik, Universität Bremen, Bremen, doi:10.1594/PANGAEA.815111, 2013.

Istomina, L., Heygster, G., Huntemann, M., Schwarz, P., Birnbaum, G., Scharien, R., Polashenski, C., Perovich, D., Zege, E., Malinka, A., Prikhach, A., and Katsev, I.: Melt pond fraction and spectral sea ice albedo retrieval from MERIS data Part 1: Validation against in situ, aerial, and ship cruise data, The Cryosphere, 9, 1551-1566, doi:10.5194/tc-9-1551-2015, 2015.

Kalnay, E., Kanamitsu, M., Kistler, R., Collins, W., Deaven, D., Gandin, L., Iredell, M., Saha, S., White, G., Woollen, J., Zhu, Y., Leetmaa, A., Reynolds, R., Chelliah, M., Ebisuzaki, W., Higgins, W., Janowiak, J., Mo, K. C., Ropelewski, C., Wang, J., Jenne, R., and Joseph, D.: The NCEP/NCAR 40-Year Reanalysis Project, B. Am. Meteorol. Soc., 77, 437-471, doi:10.1175/15200477(1996)077<0437:TNYRP>2.0.CO;2, 1996.

Mäkynen, M., Kern, S., Rösel, A., and Pedersen, L.: On the Estimation of Melt Pond Fraction on the Arctic Sea Ice With ENVISAT WSM Images, IEEE T. Geosci. Remote, 52, 7366-7379, doi:10.1109/TGRS.2014.2311476, 2014.

Perovich, D. K., Jones, K. F., Light, B., Eicken, H., Markus, T., Stroeve, J., and Lindsay, R.: Solar partitioning in a changing Arctic sea-ice cover, Ann. Glaciol., 52, 192-196, 2011.
Perovich, D. K., Meier, W., Tschudi, M., Gerland, S., and RichterMenge, J.: Sea ice, Arct. Rep. Card 2012, http://www.arctic.noaa. gov/report12/sea_ice.html (last access: 11 August 2015), 2012.

Polashenski, C., Perovich, D., and Courville, Z.: The mechanisms of sea ice melt pond formation and evolution, J. Geophys. Res., 117, C01001, doi:10.1029/2011JC007231, 2012.

Rösel, A. and Kaleschke, L.: Exceptional melt pond occurrence in the years 2007 and 2011 on the Arctic sea ice revealed from MODIS satellite data, J. Geophys. Res., 117, C05018, doi:10.1029/2011JC007869, 2012.

Rösel, A., Kaleschke, L., and Birnbaum, G.: Melt ponds on Arctic sea ice determined from MODIS satellite data using an artificial neural network, The Cryosphere, 6, 431-446, doi:10.5194/tc-6431-2012, 2012.

Schröder, D., Feltham, D. L., Flocco, D., and Tsamados, M.: September Arctic sea-ice minimum predicted by spring melt-pond fraction, Nat. Clim. Change, 4, 353-357, doi:10.1038/NCLIMATE2203, 2014.

Serreze, M. C. and Barry, R. G.: The Arctic Climate System, Cambridge: Cambridge University Press., 2005.

Shindell, D. and Faluvegi, G.: Climate response to regional radiative forcing during the twentieth century, Nat. Geosci., 2, 294-300, doi:10.1038/ngeo473, 2009.

Stroeve, J. C., Serreze, M. C., Holland, M. M., Kay, J. E., Malanik, J., and Barrett, A. P.: The Arctic's rapidly shrinking sea ice cover: a research synthesis, Climatic Change, 110, 1005-1027, doi:10.1007/s10584-011-0101-1, 2011.

Wang, C., Granskog, M., Gerland, S., Hudson, S. R., Perovich, D. K., Nicolaus, M., Ivan Karlsen, T., Fossan, K., and Bratrein, M.: Autonomous observations of solar energy partitioning in firstyear sea ice in the Arctic Basin, J. Geophys. Res.-Oceans, 119, 2066-2080, doi:10.1002/2013JC009459, 2014.

Zege, E. P., Malinka, A. V., Katsev, I. L., Prikhach, A. S., Heygster, G., Istomina, L. G., Birnbaum, G., and Schwarz, P.: Algorithm to retrieve the melt pond fraction and the spectral albedo of Arctic summer ice from satellite data, Remote Sens. Environ., 163, 153164, doi:10.1016/j.rse.2015.03.012, 2015. 